\title{
Fosterbarns skolgång och utbildning
}

\author{
BO VINNERLJUNG
}

Svenska lagstiftarehar i flera generationers barnavårdslagstiftning påtal at att fosterbarnsutbildning är en viktig fråga som måstebevakas. Trots det har praktik, tillsynsmyndigheter och forsk arevisat ett svagt intresse för hur det går för foster barn i skol an, om de lämnar vården med en hygglig utbildning eller ej. Situationen i Storbritannien och USA är radikalt annorlunda. Artikeln är en översikt av internationell forskning om problem, förklaringar och försök till lösningar.

I såväl brittisk som amerikansk barnavårdsforskning har fosterbarns skolgång och utbildning fâtt stor uppmärksamhet under det senaste årtiondet. Trots att svensk fosterhemsvård har varit föremål för mycket forskning under 80- och 90-talet, finns det nära nog inga svenska studier som närmare berör detta ämne. Undantaget är Mikael Bohmans numera klassiska undersökningar av 600 Stockhol msbarn som aktualiserades för adoption i slutet av 1950-talet, varav cirka 1/3 kom att växa upp som fosterbarn. Mer om dessa senare i artikeln. Det lilla vi vet för övrigt finns i form av fragment från olika rapporter, huvud sakligen uppföljning-

Bo Vinnerljung är fil dr och forskningsledare vid Centrum för Utvärdering av Socialt Arbete (CUS), Social styrel sen. ar av $f d$ fosterbarn $i$ vuxen ålder (Vinnerljung, 1996a, -b). Frågorna, har såvitt jag vet, sällan eller adrig diskuteras i svensk fackpress eller i rapporter från tillsynsmyndigheter, t.ex. Socialstyrelsen eller länsstyrelserna.

I USA och Storbritannien har forskningserfarenheterna identifierat ett allvarligt problem i barnavården, vilket har lett till politiska reaktioner, förändringar i policy, at frågorna prioriterats av tillsynsmyndigheter samt till en rad mer eller mindre utprövade försök att förbättra odd sen för fosterbarn att klara skolan och få en hygglig utbildning. Uppföljning av omhändertagna barns skolgång är också en central del i ett nytt brittiskt informationssystem för barnavården, utvecklat av Dartington-gruppen 
(Looking after $\mathrm{C}$ hildren, set.ex. Parker et al, 1991, Ward, 1995). Detta instrument används numera i de flesta engelska kommuner och har introducerats i Sverige av Socialstyrelsen som bedriver en försöksverksamhet i fem kommuner (Bergman, Socialstyrelsen, muntlig uppgift). Det svenska ointresset för fosterbarns skol gång är annars märkligt, eftersom flera generationers barnavårdslagstiftning har markerat betydelsen av att fosterbarn hiälps till en god utbildning (f.n. i Sol §26).

Denna artikel är en översikt av forskning på området - främst brittisk - och är skriven med syftet att försöka föra upp fosterbarns skolgång/utbildning på dagordningen som en angelägen fråga för såväl barnavårdsforskare som tillsynsmyndigheter, politiker och professionella. Observera att artikeln huvudsakligen diskuterar resultat från forskning om barn som placerats vid tidig barndom i längre tids fosterhemsvård. I Sverige är de flesta fosterhemsplaceringar av tillfällig karaktär och små barn utgör en minoritet av alla nyplacerade (Vinnerljung, 1996a).

\section{Forskning om fosterbarns skolgång under pågående vård}

Nära nog samstämmiga internationella forskningserfarenheter har över tid visat att fosterbarn i pågående vård är svagpresterande i skolan jämfört med jämnåriga i normalbefolkningen, även efter lång vårdtid (Essen et al, 1976; Fanshel \& Shinn, 1978; Jackson 1987, $1994 \mathrm{~m} \mathrm{fl}$; se även t ex; Fletcher-C ampell \& Hall, 1990; Goerge et al, 1992) I studier som använt sig av jämförelsegrupper, verkar fosterbarn (på gruppnivå) inte skilja sig från s k riskbarn som växer upp i hemmet även om förekomsten av beteendeproblem minskar under vårdtiden (Bohman 1971, 1973; Bohman \& Sigvardsson, 1980a, -b; Fox \& A rcuri, 1980; Runyan \& Gould, 1985; Heath et al, 1989, 1994; A ldgate, 1990; A ldgate et al, 1992, 1993 m fl). Bilden är dock inte helt entydig: åtminstone två amerikanska studier har visat på skolmässiga framsteg för barn i fosterhemsvård. Fanshel \& Shinn (1978) fann i sin numera klassiska undersökning av drygt 600 fosterbarn i N ew York, att de som blev kvar i vård fem år eller längre förbättrade sina betyg signifikant, och kunde ofta gå över från special klasser till normal skolgång, I Wald et als (1988) studie av 5-10 åriga barn som utsattsför misshandel eller sexuel la övergrepp i föräldrahemmet fick barn som fosterhemsplacerades en signifikant bättre utveckling i skolan än jämnåriga som blev kvar hemma efter att övergreppen upptäckts (se även diskussion i Rosenfeldt et al, 1997). ${ }^{1}$ Trots dessa avvikande röster från USA sammanfattas ibland problemet i brittisk litteratur ungefär i följande pessimistiska ord: »effekten av fosterhemsvårdens påverkan på barns skola och utbildning verkar som bäst vara neutral«(bl.a. i Berridge, 1994, 1997).

Mikal Bohmans banbrytande och internationel lt mycket uppmärksammade studier av de 600 adoptionsaktuella spädbarnen nämndesi inledningen. I grova drag blev 1/3 adopterade och $1 / 3$ återvände hem till sina mödrar efter att dessa återkallat sina adoptionsmedgivande. Den resterande tredjedelen blev fosterbarn, oftast p ga mis-

1 En liknande opublicerad studie citeras i Sawyer \& Dubowitz, 1994. 
stänkt dålig hereditet, exempelvis vid tecken på försenad utveckling eller när det fanns «socialt handikapp « i släkten som alkoholism, kriminalitet eller mental sjukdom (Hedberg, 1964; Bohman, $1970 \mathrm{~m} \mathrm{fl}$ ) I olika uppföljningar från 11 till 23 års ålder jämfördes sedan grupperna med varandra och med en kontrollgrupp bestående av jämnåriga av samma kön som valts slumpvis från de 600 barnens skolklasser. I två av dessa uppföljningar - när barnen var 11 och 15 år - jämfördes betyg samt lärarskattningar av barnens beteende och skol prestationer. Vid framförallt 15 år kom fosterbarnen allvarligt till korta jämfört med adoptivbarn och kontroller. De befann sig på samma betygsnivå som de adoptionsanmälda barn som återvände hem - fosterpojkarna t.o.m. lägre - och var i många fall föremål för undervisning i hjälpklass eller liknande (Bohman, 1971, 1973; Bohman \& Sigvardsson, 1980a, -b; översikt i Lagerberg, 1984 och i Vinnerljung, 1996a; -b). Bohman och hans medarbetare Sören Sigvard sson menade att resultaten »trots noggranna analyser « inte kunde förklaras med att fosterbarnen hade en mer belastad ursprungsbakgrund än barn som blev adopterade eller återvände hem (Bohman och Sigvardsson, 1980c, s 9; se dock C ederström, 1990 för kritik).

För övrigt finns det i Sverige några mindre undersökningar där forskarna nämner att fosterbarn har problem i skolan (Djurfeldt et al, 1976; Eriksson et al, 1989; A ronsson \& Hagberg, 1993; de två sista ref.

2 Ytterligare referenser och diskussion finnsi Vinnerljung 1996a, -b, för svenska exempel se bl.a. V innerljung, 1992, fenomenet finns även i brittisk barnavårdshistoria, se bl.a. Triseliotis, 1980. berör barn till kvinnor som missbrukat under graviditeten; se översikt i Vinnerljung, 1996b). Det finns bara en äldre svensk studie av 200 fosterbarn i Värmland som inte pekar åt samma håll. I lärarskattningar som gjordes 1957 befanns bara runt vart femte fosterbarns skolprestationer vara sunder medelmåttan«(C arlsson, 1972, s70).

\section{Forskning om vuxna foster- barns utbildning}

En liknande bild tonar fram om vi betraktar fosterbarn i vuxen ålder. En rad undersökningar har funnit att fosterbarn löper stor risk att lämna vården som lågutbild ade (Palmer, 1979; Triseliotis, 1980; Zimmerman, 1982; Festinger, 1983; Jones \& M oses, 1984; Triseliotis \& Russel, 1984; Barth, 1990; Fanshel et al, 1990, Cook, 1991 [cit i Mech, 1994] m fl; flera brittiska sk »eaving carestudier « exempelvis Stein \& C arey, 1987; Biehal et al, 1992, 1995; Garnett, 1992). Undantaget är en stor svensk studie, åter igen med data från 1950-talet (Berglind, 1956, f ö se översikt i Vinnerljung 1996a). De studier som använt sig av jämförelsegrupper har vanligen funnnit at vuxna fosterbarn är lika lågutbildade som personer vilka växt upp i utsatta hemiljöer (Ferguson, 1966; Dumaret, 1985; Christoffersen, 1993).

I Vinnerljungs doktorsavhandling om vuxna fosterbarn användes bl.a. registerdata om utbildning för jämförelser mellan 107 fosterbarn födda 1958-67, som haft sin huvud sakliga uppväxt i fosterhemmet, och deras 128 syskon på mödernet vilka vuxit upp hemma. Resultaten visade inga signifikanta skillnader i utbildningsnivå mellan foster- 
Tabell 1 (från Vinnerljung, 1996a):

Fosterbarn och »hemmabarn « födda 1968 eller tidigare, jämförda med i Sverige födda 2534-åriga barn till ej fackutbildade arbetare och barn till »mellantjänstemän « (enl SCB, 1993)

\begin{tabular}{|c|c|c|c|c|}
\hline & $\begin{array}{l}\text { Grundskola } \\
\text { el mindre }\end{array}$ & $\begin{array}{c}\text { 2-årigt } \\
\text { gymnasium }\end{array}$ & $\begin{array}{l}\text { 3-4 årigt } \\
\text { gymnasium }\end{array}$ & $\begin{array}{l}\text { Högskole- } \\
\text { utbildning }\end{array}$ \\
\hline \multicolumn{5}{|l|}{ Män } \\
\hline Fosterbarn $(n=62)$ & $40 \%$ & $48 \%$ & $8 \%$ & $3 \%$ \\
\hline Hemmabarn $(n=58)$ & $40 \%$ & $48 \%$ & $9 \%$ & $3 \%$ \\
\hline Barn till ej fackutbildade arbetare & $28 \%$ & $53 \%$ & $8 \%$ & $12 \%$ \\
\hline Barn till »mellantjänstemän« & $11 \%$ & $37 \%$ & $15 \%$ & $37 \%$ \\
\hline \multicolumn{5}{|l|}{ Kvinnor } \\
\hline Fosterbarn $(n=40)^{3}$ & $40 \%$ & $45 \%$ & $3 \%$ & $12 \%$ \\
\hline Hemmabarn $(n=61)$ & $56 \%$ & $31 \%$ & $10 \%$ & $3 \%$ \\
\hline Barn till ej fackutbildade arbetare & $23 \%$ & $53 \%$ & $9 \%$ & $15 \%$ \\
\hline Barn till »mellantjänstemän & $9 \%$ & $37 \%$ & $17 \%$ & $37 \%$ \\
\hline
\end{tabular}

barn och «hemmabarn« vid uppföljning då syskonen var 25-35 år. Fosterflickorna tenderade dock att vara bättre utbildade än »hemmaflickorna« Däremot hade båda grupperna - i synnerhet männen - påtagligt lägre utbildningsnivå än jämnåriga `’arn till icke fackutbildade arbetare« vilket är den mest lågutbildade gruppen i SC B:s statistik när utbildning tabuleras efter föräldrars yrke (Vinnerljung, 1996a; SCB, 1993).

I utländ ska studier har vuxna fosterbarn beklagat att de inte fătt/lyckats skaffa sig bättre utbildning under vårdtiden (Festinger, 1983; Stein \& C arey, 1987; Fanshel et al, 1990; G arnett, 1992 m fl). Dåliga skolprestationer under vårdtiden är en relativt stark förutsägande faktor för «negativt utfall «hos fosterbarn i vuxen ålder (Berglind, 1956; Ferguson, 1966; Zimmerman, 1982; Festinger, 1983; Fanshel et al, 1990; C hristoffersen, 1993). I V innerljungs syskonstudie var lågutbildning starkt samvarierande med al Ivarliga ekonomiska problem i vuxen ålder
(Vinnerljung, 1996a). En brittisk sk » leaving care«-rapport från 1995 visade - som väntat - att utbildning var nyckelfaktorn till att fosterbarn skulle få en hygglig ingång till arbetsmarknaden (Biehal et al, 1995).

\section{Varför är det så här?}

Forskningen har hittills inte lämnat något konklusivt svar på frågan svarför är det så här?« Det mest ambitiösa europeiska försöket att lösa gåtan är den brittiska $\gg 0$ xfordstudien «(jämför Fanshel \& Shinn, 1978 som använde avancerad multivariatanalys i sin longitudinella studie av fosterbarn från $\mathrm{N}$ ew York). M ot bakgrund av att $\mathrm{O}$ xfordstudien rönt stor uppmärksamhet i främst brittisk vetenskaplig press, och är kontinuerligt

3 Eftersom gruppen fosterf lickor är så liten blir de numeräratalen bakom procentsiffrorna mycket små, vilket gör att skillnaderna mellan fosterflickor och hemmaflickor inte är statistiskt signifikanta. 
föremål för återkommande referat och citeringar, görs i följande avsnitt en detaljerad genomgång av resultaten.

\section{0 xfordstudien}

I undersökningen följdes skol gången under tre år för 49 fosterbarn 8-14 år. Dessa jämfördes kontinuerligt med 58 barn som var föremål för andra barnavårdande åtgärder men som aldrig varit intagna i dygnsvård. Barnen bedömdes komma från någorlunda jämförbaraursprungsfamiljer. ${ }^{4}$

Resultaten visade att fosterbarnen hade lika svaga skol resultat som jämförelsegruppen, och att de inte gjorde mer framsteg över tid än de utsatta barnen som bodde hemma. Forskarna - Jane A ldgate, M atthew Colton och A nthony Heath - har i en rad artiklar med hjälp av empiriska data prövat olika förklaringar till dessa resultat, som forskarna naturligt nog fann nedslående (Heath et al, 1989, 1994; Aldgate, 1990; Aldgate et al, 1992, 1993; C olton \& Heath, 1994; Colton et al, $1995 \mathrm{~m} \mathrm{fl}$ ). De fann bland annat:

- specialundervisning i skolan verkade inte ha haft några effekter (jfr Lagerberg et al, 1994)

- de svaga skolprestationerna kunde inte förklaras med att lärarnas förväntningar

4 Jämför Andersson, 1984, 1995 och Packman, 1986 som båda inte fann några avgörande skollnader mellan barn som slutligen kom i längre samhäll svård och de som återvände hem efter en kortare vistelse på barnhem (A ndersson) eller som aldrig togs in i samhäll svård efter utredning påsocial byrån (Packman).

5 Jämför $\mathrm{G}$ eorge et a., 1992, som i en större undersökning av Illinoisfosterbarn fann att behovet av specialundervisning ökade ju längre barnen var placerade. på eller attityder till fosterbarnen.

- även om det var färre fosterbarn än barn från jämförelsegruppen som hade beteendeproblem, verkade detta inte påverka skol prestationerna. A nnars är just närvaron av sådana problem vanligtvis en stark förklaringsfaktor för skolsvårigheter hos barn (se t.ex. Colton et al, 1991).

- längden på placeringen gjorde inte någon skillnad (jfr Fanshel \& Shinn, 1978 som inte heller fann något starkt samband mell an vårdtid och skolprestationer). Urvalet var av tvärsnittstyp - alla barn i vård vid ett visst tillfälle - med huvudsakligen mycket långa placeringstider. Medianfosterbarnet hade vid undersökningens början varit 7 år i vård.

- stabiliteten i placeringarna kunde inte hellre förklara resultaten (inte heller Fanshel \& Shinn, 1978 fann ett samband mell an skolresultat och antal placeringar under vårdtiden). Fosterbarn som sluppit sammanbrott i fosterhem eller som adopterades efter många år i vård klarade inte skolan signifikant bättre än barn utan denna bakgrund. Det fanns t.o.m. en tendens till att de barn som återvände hem klarade sig bättre (A ldgate et al, 1992). Däremot diskuterar Jane Aldgate i en av artiklarna (A ldgate, 1990) att barnens uppl evelser av permanens i placeringen - inte placeringens form - visade sig vara positivt korrelerad med bättre resultat i skolan.

- barnens svårigheter i skolan kunde inte skyllas på att fosterföräldrarna hade svagt intresse eller engagemangi barnens skolarbete. Studien visade tvärtom đt fosterföräldrarna vanligtvis var aktiva i att hjälpa barnen med skolarbetet, i att 
delta vid lärarsamtal etc och var så i avsevärt högre grad än jämförelsegruppens mammor och pappor.

- fosterföräldrarnas sociala bakgrund hade inget signifikant samband med hur bra el ler dåligt det gick för fosterbarnen i skolan (samma resultat som i Fanshel \& Shinn, 1978). Däremot fanns tydliga tendenser att barn med tidig placering i högutbildade familjer klarade sig bättre (Heath et al, 1994; jfr Fanshel \& Shinn, 1978).

- den starkaste förklaringsfaktorn var barnens bakgrund före placering. De som hade placerats på grund av »abuse«(misshandel eller andra övergrepp) eller sneglect «(bristande omsorg) hade sämre skolprestationer än barn som kommit i vård av andra skäl (jfr Howe, 1995 om adopteradebarn).

Forskarna konstaterar att fosterhemsvården misslyckats med att ge barnen en sutväg ur utsatthet $\ll^{6}$ De drar slutsaten att det inte räcker med en »vanlig« hygglig familj för att kompensera fosterbarn för deras dåliga utgångsläge:

Thus, something more than »normal «family life and «normal «parental interest may be required to compenste for earlier deprivation. 0 ur foster parents were in general an average group in terms of their social class and educ ation...... Is it perhaps so suprising if, when vaverage educational inputs are given to children with rabove average« educational needs, they fail to

6 Titeln på en av artiklarna (H eath et al, 1994) är Failure to escape, en parafrasering av titeln på en berömd studie av arbetarklassungdomar och utbildning: Escapefrom disadvantage (Phillip, 1990). make sgreater than average« educational progress? (Colton et al, 1995 s 34; jfr Runyan \& G ould, 1985 som drog samma slutsats utifrån studier av amerikanska fosterbarns skolgång).

Det finns dock problem med studien, som begränsar dess generaliserbarhet. 49 barn är ett litet sample. Undersökningen baseras dessutom på ett tvärsnittsurval av barn som har varit i vård under många år redan då studien inleds. Forskarna saknar följaktligen den typ av data som de fătt om undersökningen hade varit av longitudinell typ, där barnen följts från placeringens början.? Uppgifter om barnens bakgrund före placeringen är knapphändiga, förutom orsaken till placering. Slutsatserna om att det är förhållandena före vård som avgjort fosterbarnens öde i skolan vilar $\mathrm{m}$ a 0 delvis på svag empirisk grund, enligt min mening.

I följande avsnitt diskuteras de förklaringar som presenterats i andra studier, explicit eller implicit. 0 bservera att alla undersökningar som diskuterasi denna artikel utgår från betraktelser av fosterbarn på gruppnivå. Spridningen inom gruppen fosterbarn är stor. Självfallet är det inte så att alla - kanske inte ens majoriteten - fosterbarn är svaga i skolan el ler blir lågutbildade, men risken är mycket större än för jämnåriga i normalpopulationen.

\footnotetext{
7 Ett exempel på longitudinell forskning om fosterbarn är det svenska Barn-i-kris-projektet, se bl.a. Hessle, 1988: Börjeson \& Håkansson, 1990; C ederström, 1990, 1994.
} 


\section{Förklaringar med fokus på fosterbarnens genetiska förutsättningar}

De flesta studier av vuxna $f d$ fosterbarn har baserats på långtidsplaceringar. När amerikanen Henry Maas (1969) gjorde en tioårsuppföljning påsin och Richard Englers klassiska 50-tals studie C hildren in need of parents (1959) fann han att långtidsplacerade barn hade signifikant lägre IQ än fosterbarn som återvände hem. Även Fox och A r curi (1980) fann lägre IQ än medel hos 163 (huvudsakligen svarta) amerikanska fosterbarn som varit i vård i genomsnitt fem år, när dessa undersöktes med standardiserade tester.

Men franska studier av syskonkullar från fattiga familjer som fick ol ika uppväxtöden talar mot hypotesen att allt bara handlar om en statisk, oföränderlig begåvning från födseln. En grupp barn adopterades av välbeställda, högt utbildade adoptivföräldrar. $N$ ästan alla dessa barn blev högpresterande i skolan. De jämfördes i sena tonåren med sina biologiska syskon som växt upp hemma eller i fosterhem. I 'hemmabarnsgruppen « blev de flesta lågpresterande i skolan medan alla syskon som växte upp i fosterhem betecknandes som »school failures« (Schiff et al, 1978; 1982; Dumaret, 1985).

Majoriteten av studier, särskilt de med jämförelsegrupper, har liksom de franska forskarna fokuserat på barnens utveckling över tid och har inte betraktat begåvning eller inlärningsförmåga som en statisk egenskap (se t.ex. Fanshel \& Shinn, 1978). Ett svenskt exempel är Bohmansforskning, som refererades tidigare. Medan alla tre grupperna - adoptivbarn, barn som återvänt till sina mammor och fosterbarn - var lågpres- ter ande under de första skolåren hade adoptivbarnen i 15-årsåldern kommit ifatt ett normalmaterial medan de andra två grupperna - särskilt fosterpojkarna - fortfarande hade påfallande stora skolproblem (se sammanfatning i Vinnerljung, 1996a, -b).

Sammantaget verkar det på gruppnivå inte finnas något starkt stöd för hypotesen att fosterbarns skolsvårigheter enbart är en spegling av deras genetiska förutsättningar. Forskningen pekar mer på en hämmad kognitiv utveckling för fosterbarn, att många är och riskerar att förbli underpresterande (jfr Fanshel \& Shinn, 1978, som dock fann att skolresultat efter fem års vårdtid bättre kunde förklaras av barnens IQ än vid placeringens början).

\section{Förklaringar med fokus på fosterbarns erfarenheter i sina ursprungshem.}

Den vanligaste hypotesen som framförts är at tidiga trauma eller emotionella skador påverkat barnens kogniti va utveckling, t.ex. i den tidigare refererade 0 xfordstudien. Förklaringen förankras oftast i psykologisk teoribildning som betonar vikten av de tidiga levnadsåren och kvaliteten i de ursprungliga relationerna (se t.ex. Fox \& A rcuri, 1980; Timberlake et al, 1987; Saywer \& Dubowitz, 1994; Rosenfeldt et al, 1997). De empiriska bevisen för antagandet är i en del studier enligt min mening bristfälliga. Ibland verkar det istället som om denna slutsats görs i brist på de förklaringar som empirin kan ge. Valida data om tidiga negativa livserfarenheter är mycket svåra at fånga för en forskare, särskilt retrospektivt. Men det är möjligt. Fanshel \& Shinn (1978) fann att en åldersnormal utveckling före 
placeringen (enligt information från barnens mödrar) ökade chansen att fosterbarnen skulle förbättra sina skolresultat under vårdtiden. Vissa forskare menar att det sannolikt är kombinationen av tidiga dåliga uppväxterfarenheter och en kompensationssvag vård som är den riml iga förklaringsmodellen (t.ex. Essen et al, 1976).

Däremot är det sällan som barns separationserfarenheter (t.ex. vid en viss ålder) lyfts fram som en särskild förklaringsfaktor i de utländska studierna. Detta beror kanske på att fosterbarn ofta jämförts med adopti vbarn, som också varit med om separationer men som klarar sig markant bättre i skolan. Det svenska Barn-i-Kris projektets betoning på separation som främsta kausala faktor för fosterbarns utveckling (se bl.a. Vinterhed et al, 1981, Börjeson \& Håkansson, 1990) är mer ovanlig i utländsk forskning om samhällsvårdade barn. Där lutar man sig oftare mot en forskningstradition som avvisar hypotesen att barn skadas ovillkorligt på lång sikt av separationer, och som menar att det främst är kroniska missförhållanden under lång tid som har skadliga effekter (t.ex. Clarke \& Clarke, 1976; Lewis et al, 1984; Q uinton \& Rutter, 1976; Rushon \& Treseder, 1976; Schaffer, 1990). Är det så att regelbundet umgänge fosterbarn-föräldrar, vilket kan antas mildra verkningarna av en separation, minskar risken för skolproblem? Frågan, som i en vidare mening berör kopplingen mellan kognitiva och emotionella funktioner, har bara i ett fătal undersökningar stäl lts till insamlad empiri. I 0 xfordstudien var det ingen signifikant skillnad i skolprestationer mellan fosterbarn som hade regel bundet umgänge med föräldrarna och de som inte hade det (A ldgate et al,
1992). Inte heller Fanshel \& Shinn (1978) fann några samband mellan förbättrade skolprestationer under vårdtiden och föräldrarnas besök. Vinnerljung (1996a) fann efter multivariatanalys av resultaten från den tidigare nämnda uppföljningen i vuxen ålder av fosterbarn och deras hemmaboende syskon, att ett någorlunda regelbundet umänge barn-föräldrar minskade risken för låg utbildning i vuxen ålder. Det är annars ovanligt med tydliga statistiska samband mel lan fosterbarns situation som vuxna och deras umgängeshistoria under placeringen (se översikt i a a). Författaren varnar dock för generaliseringar utifrån detta enstaka analysresultat, som heller inte har någon mosvarighet i andra utfall som undersöktes i studien.

\section{Förklaringar med fokus på fosterhemmen}

Oxfordstudien pekade på att fosterföräldrar inte är en högutbildad grupp (jfr A linÅ kerman, 1978; Bohman I, 1982; Triseliotis, 1983; Vinterhed, $1985 \mathrm{~m} \mathrm{fl}$ ) . John Triseliotis har använt denna förklaring till att de vuxna fosterbarnen $\mathrm{i}$ hans studier är påtagligt lågutbild ade, vilket han menade speglade fosterhemmens utbildningstraditioner (Triseliotis \& Russel, 1984). Även Mikael Bohman har i flera publikationer berört denna förklaringsmöjlighet (se diskussion i Vinnerljung, 1996a), men har varit mer tveksam till dess värde, eftersom fosterföräldrarna utbildningsmässigt befann sig på en normal populationsnivå. En annan rimlig invändning finns också i den statistik som användes i Vinnerljungs registerstudie (a a), där vuxna fosterbarn var påtagligt sämre utbildade än barn till »xicke fackutbildade 
arbetare« De verkar med andra ord inte ha fölit med i sin generations al Imänna utveckling mot att få högre utbildning än sina föräldrar.

Observera också att fosterföräldrarna i den refererade 0 xfordstudien var mer engagerade i sina fosterbarns skola än jämförelsegruppens mammor och pappor. Däremot har andra studier visat att brittiska fosterföräldrar ofta är osäkra på ansvars- och arbetsfördelningen mellan fosterhem och socialarbetare när det gäller barnens skola (C liffe \& Berridge, 1991) samt att de anser sig ha dåligt stöd från socialvården i dessa frågor (Fletcher-C ampell \& Hall, 1990).

Sonia Jackson (1988) har pekat på de uppenbart stora skillnaderna mellan adoptivbarns och fosterbarns utbildningsresultat, där fosterbarn al ltid förlorar i jämförelsen. Hon argumenterar för att detta beror på att adoption innebär ett livslångt åtagande för (ersättnings-) föräldrarna, vilket leder till att adoptivföräldrar förväntar sig samma prestationsnivå som om barnen varit deras egna ’’biologiska« Jämförelsen är delvis tveksam. De adoptivbarn vi vet mest om från forskningen har placerats i yngre ålder än majoriteten av fosterbarn. Sedan tillkommer, vilket Jackson också noterar, att adoptivföräldrar vanligtvis är bättre utbildade och befinner sig ett snäpp högre på socialgruppsstegen än fosterföräldrar. De är vad utvecklingspsykologen Sandra Scarr kallar en »above average group « (Scarr \& Grajek, 1982 s 365; jfr Alin-Å kerman, 1978; Bohman I, $1982 \mathrm{~m} \mathrm{fl}$ ). Fletcher-C ampell \& Hall (1990) menar dock att det är en gåta, att de förhållanden som uppenbart finns i adoptivhem, inte kan replikeras i fosterhems- eller i institutionsvård genom bät- re ansträngningar eller annorlunda attityder från vårdarna.

En annan tänkbar skillnad är de olika förväntningar på adoptivbarn respektive fosterbarn som finns när de kommer till sin 'ทya«familj. A doption är en positiv händelse och adoptivföräldrarna vet att den överväldigande majoriteten adoptivbarn går en normal utveckling till mötes. En fosterhemsplacering är per definition en lösning av sociala problem och fosterbarn blir explicit eller implicit definierade som bärare av sproblem《 A nekdotiska bevis från det sociala arbetets praktik pekar på att socialarbetare och fosterföräldrar tenderar at fokusera mer på avvikelser i fosterbarns anpassning och utveckling än på det normal $a{ }^{8}$ Ibland görs antaganden om att yngre fosterbarn har dolda störningar som troligen visar sig senare, t.ex. i tonåren (nämns t.ex. ofta som en välmenande varning vid rekrytering av fosterhem). Hur påverkar detta fosterföräldrarnas förväntningar på eller ambitionsnivå för barnens skolarbete? M ig veterligt finns nära nog ingen forskning om just detta (jfr dock Cautley, 1980), men det verkar vara en angel ägen fråga att undersöka, kanske som en empirisk syn av olika praxisuppfattningar .

8 Jämför Proch \& Taber, 1987 och Timberlake \& Verdieck, 1987 som menar att fosterhemsvården primärt har barns anpassningi fosterhemmen som mål. Det är m.a.o. barnens socialisering och inte personligautveckling som står i centrum för vårdsystemets ambitioner och intresse. »Nonconforming children and youth pay for being different or for poor survial skills in interpersonal relationships by being shipped from one foster home to the next until they learn at least some semblance of compliance (Timberlake \& Verdieck, 1987, s.220). 


\section{Förklaringar med fokus på skolan}

Sonia Jackson (1994) har hävdat att fosterbarn är utsatta för diskriminering i det brittiska skolsystemet. Barn i samhällsvård är gravt överrepresenterade bland de elever som avstängs från den reguljära skolan (Grimshaw \& Berridge, 1994; Brodie \& Berridge, 1996). ${ }^{9}$ Hon citerar en brittisk rapport om skolskolk (C arlen et al, 1992) som fann att ett vanligt skäl till att fosterbarn skolkade var stigmatiserande behandling av lärare och översitteri från skolkamrater (som ignorerades av lärare). Studien fann också att många brittiska skolor har starka negativa fördomar mot fosterbarn och barn i institutionsvård, vilket bl.a. resulterar i att man mer eller mindre söker efter skäl att avstänga dem från skolan.

Oxfordstudien fann däremot ingen grund för hypotesen att fosterbarns svårigheter i skolan skulle bero på låga förväntningar från lärare eller negativ särbehandling (t.ex. Heath et al, 1994). Flera brittiska forskare har allmänt konstaterat att fosterbarn ware not well served by the education system《 (bl.a. Colton \& Heath, 1994 s 317)..$^{10}$ Wal ker (1994) pekar på att byråkratiska problem i Storbritannien med bl.a. an-

9 Avstängning-exclusion - har under 90-talet blivit en allt vanligare strategi för att kontrollera störande barn i brittiska skol or (se Blyth \& M ilner, 1993; Brodie \& Berridge, 1996).

10 Jämför P-A Rydelius (1996) som i en översikt menar att det finns en påtagligt större risk att många av »socialtjänstens barn «blir utslagna $i$ den skolform vi har idag (efter skol reformen LGR 69), jämfört med den äldre skolan där läkepedagogiskt tänkande hade ett starkt inflytande. svarstvister, samarbetsproblem skola-socialvård ofta är hinder för fosterbarn och fosterföräldrar, vilket förvärrar barnens skolsituation (se även Fletcher-C ampbell \& Hall, 1990). Sådana problem har varit vanliga även i Sverige, bl.a. ett »Svarte-Petter spel « mel lan lokala skolmyndigheter och den placerande kommunen om vem som ska betala för stödinsatser i skolan. Detta ledde nyligen till en lagförändring. Fr.o.m. juli 1997 ger Socialtjänstlagens $72 \S$ den placerande kommunen ful lt kostnadsansvar för personligt stöd i skolan till fosterbarn, om behoven är relaterade till sociala eller psykologiska skäl. ${ }^{11}$

\section{Förklaringar med fokus på socialvården}

Flera såväl brittiska som amerikanska forskare har lagt skulden på socialvården, på dess ointresse för fosterbarns skol gång och utbildning, för dess oförmåga att hjälpa fosterföräldrar och barn eller på dess otillräckliga resurser alternativt dess användning av resurserna. Sammantaget berör dessa förklaringar flera olika ni våer av det sociala arbetet. Den främsta brittiska representanten för synsättet är Sonia Jackson, som konstaterđ att vårdsystemet är så bristfälligt i dessa avseenden att det sannolikt lägger mer sten på bördan istället för att kompensera barnen för deras dåliga start i livet (Jackson, 1987; 1994). Hon har lyft fram de låga förväntningar som vårdsystemet har på fosterbarns skolprestationer och manat till omfattande förändringar i såväl policy som praxis, bl.a. i de professionellas prioritering-

11 Se Svenska Kommunförbundets C irkulär 1997:202 för närmare beskrivning. 
ar (Jackson, 1987; jfr Rowe et al, 1984).

Det finns störande bevis i brittisk forskning på just social vårdens brister $\mathrm{i}$ att hantera fosterbarns skol gång. M ycket få lokala barnavårdsmyndigheter har interna riktlinjer för hur skolfrågor ska bevakas (se diskussion i Berridge, 1994). Fletcher-C ampell \& Hall (1990) fann i en detaljerad studie av 400 barn (2/3 fosterbarn), placerade i samhällsvård av 43 kommuner, att majoriteten hade någon form av skolproblem. Men forskarna noterade att det sällan fanns en begriplig dokumentation av barns problem/ framsteg i skolan hos socialvården (se även Ward, 1995), att samarbetet socialvård-skola varierade mycket och att socialarbetarna överhuvudtaget visste lite om vad som hände i skolan. Det var bara i undantagsfall som barns skol gång beaktades vid beslut om placering eller vid omplaceringar i vård systemet. Flera brittiska studier har pekat på att de skolbyten som vanligen följer av placering i vård, och av omplaceringar, ofta är direkt skadliga för fosterbarns utveckling i skolan (Berridge \& C leaver, 1987; FletcherCampell \& Hall, 1990; Cliffe \& Berridge, 1991; Biehal et al, 1995; se andra citeringar i Berridge, 1997). I Fletcher-C ampell \& Falls (1990) undersökning hade en tredjedel av barnen inga problem i skolan. Denna grupp dominerades av barn som varit i stabil vård under flera år. M ånga hade sluppit byta skola när de placerades. Robert $\mathrm{G}$ oerge har t.o.m. jämfört amerikanska fosterbarn med smigrant farm workers« lantarbetare som lever i ständig flyttning mellan t.ex. olika fruktodlingar över kontinenten.

The plight of foster children is similar in one respect to that of the children of migrant farm workers in that they often move from one school to the next, but for foster children it is also the case that they may move several times from one set of foster parents to the next. Unlike the case of migrant workers children, no research on special-education services to foster children has been done (G oerge et al, 1992 p 421).

Det är dock tveksamt om ensidig fokusering på stabilitet ger oss en huvudförklaring. I Oxfordstudien hade denna faktor inget starkt förklaringsvärde, liksom i Fanshel \& Shinns N ew York-undersökning. Den stora majoriteten - 75 procent - av de vuxnafosterbarnen i Vinnerljungs syskonstudie (1996a) hade bott i samma fosterhem under hel a uppväxten och hade oftast placeras när de var tre år eller yngre. Efter multivariatanalys av data hade byte av fosterhem under vårdtiden ett svagt och osäkert förklaringsvärde för utbildning i vuxen ålder.

Richard Barth är den forskare som tydligast visat på skol/utbildningsproblem för amerikanska fosterbarn. Även han lägger det huvudsakliga ansvaret på vårdsystemet: återkommande flyttningar, svagt stöd från fosterföräldrar, socialvårdens bristande intresse och förståelse för skol ans betydelse i fosterbarns liv $m \mathrm{~m}$. Han har dock mest intresser đa sig för olika insatser som syftar till at förändra förhållandena, verksamheter som försöker förbereda fosterbarn för ett eget vuxenliv efter långvarig samhällsvård (bl.a. Barth 1986, 1990).

Även om brittiska nationella myndigheter - i motsats till de svenska - har reagerat starkt på forskningsrapporterna och manat till förändring (set.ex. rapporten Patterns\& Outcomes in Child Placement från motsv socialdepartementet, 1991) verkar det i 
praktiken ha hänt relativt lite. När tillsynsorganen för socialvård och utbildning gjorde en gemensam undersökning av 1.600 barn i samhällsvård, blev bilden i deras rapport tydlig:

The care and education systems in general are failing to promote the educational achivements of children who are looked after. The standards which children achieve are too low and often the modest progress they make in primary schools is lost as they proceed through the system. Despite the clear identification of this problem in several research studies and by local comittees of enquiry, little has been done in practice to boost achievement (Dept of Heath Social Services Inspectorate and Office for Standards in education, 1995 p 3 i Summary report)

Utredningen fann att bristerna kunde skyllas på den låga prioriteten som skolfrågor har för socialvården, frånvaron av riktlinjer i kommunerna, samarbets-/byråkratiska problem mellan skola och socialvård $\mathrm{m} \mathrm{m}$ - alla de brister som tidigare forskningsrapporter framhåll lit.

Maria Newsome (1992) har i en artikel diskuterat varför den brittiska socialvården har/har haft lite intresse för fosterbarns skola/utbildning. Hon menar att orsakerna till stor del finns i barnavårdens historia. Fosterbarn hade tidigare en roll som okvalificerad arbetskraft och som brickor i det brittiska imperiebygget. ${ }^{12}$ Ännu i mitten av

12 Jämför H olt, 1994 om amerikanska fosterbarn som med särskilda s.k. orphans trains en masse skickades ut till västern för att befolka nybyggarsamhäl lena med billig arbetskraft. Se även Barbal et, 1983 om den australiska fosterhemsvårdenshistoria. 1950-talet skickade England fosterbarn till Kanada. Newsome menar att samhällsvård historiskt har varit och fortfarande är främst ett kontrollinstrument. Samhället/ socialvården har aldrig sett utbildning som ett sätt att ge fosterbarn gynnsamma möjligheter i framtiden. Såväl Sonia Jackson (1987) som Harriet Ward (1995) har pekat på att det i vissa (brittiska) barnavårdskretsar finns motstånd mot ambitionen att ge omhändertagna barn bättre utbildning än vad de skulle fătt om de blivit kvar hemma (jfr Barbalet, 1983 om A ustraliens fosterhemsvård under första hälften av 1900-talet). I den tidigare citerade studien av Fletcher-C ampell \& Hall (1990) konstaterar författarna att nära nog ingen av de intervjuade socialarbetarna, institutionspersonalen eller fosterföräldrarna nämnde att utbildning жan förändra människor « eller tillfredsställa behov som fosterbarnen hade, kort sagt att utbildning hade ett värde i sig själv för barn i samhäl Isvård. I studien framkom istäl let att ....education within the context of consideration of children in care was not seen as something that had to be debated - it waslargely a non-issue (p 162).

\section{Summering}

Nära nog alla forskare har sett samma fenomen, i USA, Storbritannien och i Sverige. Däremot har meningarna om vad som orsakar fosterbarns problem med skola/utbildning varierat, när man letat efter en huvudsaklig förklaring, t.ex. vårdformens instabilitet. A ll a förklaringar verkar ha brister i något avseende, de motsägs av andra studier etc. Det verkar svårt att med ledning av forskningsresultaten entydigt argumentera för att den ena förklaringen är så mycket 
mer trovärdig än den andra. Detta gäller även, enligt min mening, hypotesen att det enbart är barnens erfarenheter före placering som bestämmer deras skol prestationer. Kanske visar de olika resultaten också på variabelanalysens begränsningar, framförallt när olika undersökningar som syftat till att få fram kausal samband jämförs med varandra (Ekström, 1993). Förekomsten av disparata variabelkonstruktioner och -definitioner speglar sannolikt också avsaknaden av relevant, empirisk förankrad teori.

En mer rimlig men något schablonmässig hypotes är att det finns flera orsaker som samvarierar och som gör det på olika sätt för olika grupper av fosterbarn, t.ex. i form av aggregerade riskfaktorer/processer eller kedjor av skadliga livserfarenheter (jfr t.ex. Sameroff et al, 1987; Hessle, 1988). Liksom på andra områden som behandlar barns utveckling över tid, är enfaktoriella förklaringsmodeller sällan användbara. Men den central a frågan återstår: är förhållandet påverkbart, och i såfall hur?

\section{Försök till förändringar eller lösningar}

I avsnittet redovisas de förslag till förändringar och de exempel på insatser med syfte att förbättra fosterbarns skol- och utbildningssituation som jag stött på i litteraturen.

\section{Förändra rekryteringen och/ eller skolningen av fosterföräldrar}

Flera författare har diskuter đt möjligheten att i högre grad välja välutbildade människor som fosterföräldrar, men har avvisat tanken (Lagerberg, 1984; Heath et al, 1994 m fl). Jackson (1987) menar dock att större vikt bör läggas på förmågan att hjälpa barn med skola/utbildning vid urval och träning av fosterföräldrar (se även Fletcher- $C$ ampell $\&$ Hall, 1990).

Det finns dock inga konsistenta resultat från barnavård sforskningen som stöder hypotesen att fosterhemsvården skulle bli bättre om socialtjänsten oftare än nu rekryterade fosterföräldrar med hög utbildning. En varnande paradox finns dessutom i flera amerikanska adoptionsstudier (både små och äldre barn) där risken för sammanbrott ökade signifikant om adoptivmodern var högskoleutbildad (Barth \& Berry, 1988; Berry \& Barth,1990; Rosenthal et al, $1988 \mathrm{~m} \mathrm{fl).}$

\section{Stöd åt fosterföräldrar i deras arbete med fosterbarns skola och utbildning}

Det finnsfå exempel på insatser som systematiskt riktats mot fosterföräldrarna, t.ex. för att hjälpa dessa att bättre stödja sina fosterbarns skolarbete, och mig veterligen ingen sådan satsning som utvärderats. Triseliotis et al (1995a) nämner ett par brittiska lokala projekt i en översikt av familjevårdens teori och praktik.

\section{Socialvården tar ett större ansvar genom speciella insatser}

Det mest substantiella brittiska exemplet på ökade insatser direkt i socialvårdens regi är en verksamhet som bedrivsi $M$ anchester. M an skapade 1989 en egen grupp med lärare - närmare 30 st heltidsanställda - ( $M$ anchester Teaching Service) - med arbetsuppgiften att bevaka och stödja omhändertagna barns utveckling i skolan (Walker, 1994). Lärarna ska vara barnens sutbildningsadvoka- 
ter «gentemot skolan men även i relation till den egna huvudmannen, dvs. socialvården. Varje lärare blir ansvarig för minst 10 barn och ska försäkra sig om att barnets skola/utbildning fungerar och att de insatser som krävs i skolan för att barnet ska göra framsteg verkligen blir av. A rbetsuppgifterna kan i praktiken vara av olika slag: direkt pedagogiskt stöd till enskilda barn, sortera ut byråkratiska härvor mellan skola och socialvård, kontinuerligt och regelbundet bevaka enskilda barns utveckling i skolan samt att se till at skola/utbildning har en central plats i socialvårdens kontinuerliga hantering/planering av barnets vård. Verksamheten är mig veterligen inte utvärderad. Alla $M$ anchesters fosterbarn och institutionsplacerade barn täcks av verksamheten. 1994 hade $83 \%$ ordinär skol gång, vil ket är knappt $10 \%$ fler än vad som rapporterats från andra studier av brittiska barn i samhällsvård (Fletcher-C ampell \& Hall, 1990). Nu säger det inte så mycket. En av medarbetarna, Tim Walker, beskriver verksamheten med entusiasm i en artikel publicerad i 0 xford Review of Education (Walker, 1994). Han kall ar projektet «en milstolpe«på vägen mot ett ökat ansvarstagande för fosterbarns skola och utbildning (a a, s346).

Ett annat brittiskt exempel är det läsprojekt som initierades av socialvården i Salford, kallad PRAISE (beskrivs i Menmuir, 1994). M an utgick från forskning som visade att barns skolprestationer var positivt korrelerade med hur mycket föräldrarnaläste tillsammans med sina barn och med hur mycket föräldrar stimulerade barns läsning av böcker (t.ex. Tizard \& Hewison, 1980; Tizard et al, 1982; se kort översikt i Menmuir, 1994). Grundtanken i projektet var att överföra denna kunskap om »vanliga« barn till barn i samhällsvård, med syfte att förbättra deras skolprestationer. Projektledarna delade helt enkelt ut skönlitterära böcker till fosterbarn och barn på institutioner samt instruerade fosterföräldrar eller personal att ta aktiv del i barnens läsning. Fosterföräldrar/personal läste för barnen, läste samma böcker som barnen, frågade om innehåll etc., allt efter att ha genomgått en kortare utbildning. Utvärderingen saknade data för att påvisa förändringar av före-efter typ, och hade inte heller en kontroll- eller jämförelsegrupp. Data inhämtades istället kontinuerligt från fosterföräldrar och institutionspersonal om vad de vuxna gjorde och om barnens respons. Alla barn - till mångas förvåning - läste entusiastiskt de böcker som förelogs eller som de själva valde ut. $M$ ånga valde att läsa barnböcker, egentligen avsedda för yngre barn. Ingen uttryckte några klagomål på projektet.

De mest handfasta exemplen på specialinriktade insatser finns i USA, oftast i form av «emancipationprogram « dvs. insætspaket som syftar till att förbereda nästan vuxna fosterbarn för ett liv på egen hand efter utskrivning från samhällsvård. Denna typ av sprogram« är sedan 1985 obligatoriska för alla delstaters barn- och ungdomsvård (Scannapieco et al, 1995). Innehållet varierar. Vanligtvis ingår stöd till ungdomars utbildning, insatser som of ta pågått under flera år före utskrivning från vård. ${ }^{13}$ | vissa delstater får fosterbarn kompletterande undervisning av särskilt anställda sprivatlärare« $M$ an använder sig av smentorer « som för-

13 Barth (1990) menar at insatser riktade mot fosterbarns/skola/utbildning måste påbörjas 
söker bygga upp relationer med den unge och via den vägen stöder honom/henne i skolarbetet, även med att t.ex. förändra beteendet i skolan (för beskrivande exempel, se bl.a. Rowe, 1983; Barth, 1986, 1990; Brickman et al, 1991; Scannapieco et al, 1995; Ayasse, 1995 samt ref i dessa artiklar). Resultat från utvärderingar är med något undantag positiva. Särskilt har det visat sig att programmen ökar chansen att fosterbarn lämnar skolan med fullständiga betyg (t.ex. Scannapieco et al, 1995; Ayasse, 1995; översikt i Mech, 1994; undantag är C ook, 1997 som inte finner några sådana resultat för ett lokalt remancipationsprogram《).

\section{Speciella insatser för fosterbarns utbildning som drivs av andra än socialvård och skola}

I USA finns sedan länge fristående organisationer som på olika sätt försöker hjälpa fosterbarn med deras utbildning. I några av USA 's östliga delstater har 65 privata internatskolor reserverade platser för fosterbarn, med stipendier som täcker minst $50 \%$ av kostnaderna. Resten betalas av de sociala myndigheterna. Det finns också särskilda stipendiefonder enbart för fosterbarn (Rowe, 1983; D olan \& 0 N eill, 1983; Barth, 1986).

\section{Diskussion}

\section{Sammanfattning}

Det finns en uppsjö av internationell forskning som nära nog enhetligt visar att foster-

flera år före tonåren, för att få avsedd verkan. Jämför Fanshel \& Shinn, 1978 som rekommenderar insatser under vårdtiden specifikt ämnade att förbättra fosterbarns kognitiva förmåga. barn är en lågpresterande grupp i skolan som löper hög risk att lämna vården med svag utbildning. Här uppstår genast frågan om bilden från utländska studier är överförbar till Sverige, och isåfall i vilka avseenden. Det vet vi al ltför lite om idag. Svensk forskning på området är delvis fragmentarisk, men pekar tydligt i samma riktning. Bilden verkar i internationell forskning vara förvånansvärt stabil över tid, medan svenska uppgifter snarare pekar på en försämring över tid, i och med att den allmänna utbildningsnivån successivt höjts (jfr Berglind, 1956 och C arlsson, 1972 med de citerade resultaten från Vinnerljung, 1996a).

Att fosterbarn klarar sig dåligt i utbildningshänseende är ett större »problem«idag än det var på 1950-talet, då det var normalt at bara ha obligatorisk skola bakom sig i vuxen ålder och då vuxna fosterbarn härvid inte avvek från sina jämnåriga i normalpopulationen (Berglind, 1956). Utvecklingen under främst 80- och 90-talen har i accelererande takt gått mot allt högre krav på utbildning för unga arbetssökande, vilket har lett många debattörer att spekulera om en framväxande »underklass« av lågutbildade. M ånga svagt utbildade ungdomar löper påtaglig risk att möta stora hinder i sina försök at över huvud taget komma in på arbetsmarknaden. Istället tvingas de bli socialbidragstagare under lång tid (se Salonen, 1993). Frågan om fosterbarns skola/utbildning berör med andra ord grundläggande värden om integration och normalisering av en utsat grupp där samhället har tagit över föräldraansvaret, ofta för en stor del av uppväxten. $0 \mathrm{~m}$ det är så att fosterhemsvård t.o.m. om den pågår under lång tid - i ringa grad har en kompenserande effekt på utsat- 
ta barns skol- och utbildningsprestationer är detta rimligtvisen all varlig fråga för myndigheter och professionella, sett ut det etiska perspektiv som är grunden för vår lagstiftning om interventioner i utsatta familjer.

Det finns ytterligare ett skäl för att begrunda den bild som utländsk forskning tecknar tydligt och som mer antyds i svenska studier. En av lärdomarna från utvecklingspsykopatologin är att utsatta barns livsförlopp kan förändras radikalt genom $\mathrm{s} k$ vändpunkter i unga vuxna år, möjligheter som öppnar sig t.ex. genom ett bra arbete med allt vad det innebär för självförtroende, status och delaktighet (Elder, 1974, 1986; Rutter \& Q uinton, 1984; Q uinton \& Rutter, 1988; Rutter, $1990 \mathrm{~m} \mathrm{fl}$; se även Williams \& Kornblum; 1985; Zeuner, 1990; Dalianis-Karambatzakis, 1994). G enom att utbildning idag är en central faktor för tillträde till arbetsmarknaden, reduceras sannolikheten att lågutbildade fosterbarn möter just sådana vändpunkter när de börjar sitt liv på egen hand efter skoltiden.

Svensk lagstiftning till skydd och gagn för barn har sedan decennier till bakai särskilda paragrafer uppmanat ansvariga nämnder/ kommuner att ge akt på fosterbarns utbildning (f.n. Sol §26, tidigare Bvl §§35 \& 49 samt Fosterbarnskungörelsens $§ \S 9 \& 10$ ). $0 \mathrm{~m}$ fosterbarns utbildning har varit en sickefråga«i Storbritannien, så har våra svenska lagstiftare markerat att så ska det inte vara här. Ingen har mig veterligt ifrågasatt eller problematiserat dessa ambitioner. Hur lagstiftarnas intentioner har hanterats i praktiken vet vi nära nog ingenting om från svensk barnavårdsforskning, ej heller (i motsats till Storbritannien) från utredningar el ler rap- porter från tillsynsmyndigheterna. Dessa verkar hittills ha varit ointresserade av frågan. Kanske kan försökprojektet med Dartingon-materialet vara en början till något nytt. Det finns följaktligen flera goda skäl för forskning, tillsynsmyndigheter, politiker och socialarbetare att visa större intresse för fosterbarnsskola och utbildning:

- internationell forskning är nära nog samstämmig i sin beskrivning av problembilden

- den begränsade svenska forskningen som finns på området pekar klart i samma riktning

- utländska studier innehåller rejält med sconsumer evidence« som berättar att fosterbarn själva ser bristande utbildning som ett stort problem (t.ex. Festinger, 1983; Stein \& C arey, 1987; Fanshel et al, 1990; Biehal et al, $1995 \mathrm{~m} \mathrm{fl}$ ). I Sverige är det ingen som ställt frågan, mig veterligen.

- svensk lagstiftning är tydlig

- det finns etiska/socialpolitiska bevekelsegrunder om integration och normalisering av utsatta barn, som det sannolikt råder politisk samstämmighet kring

- ingen »förlorar «på att den här frågan får större uppmärksamhet. Alla parter har här gemensamma intressen: fosterbarnen själva, fosterföräldrarna, föräldrarna och andra anhöriga. Undantaget skulle möjligen vara de vårdsansvariga kommunerna som får ytterligare en dimension av barnavården att bevaka och - vilket verkar troligt trots den ofullständiga bild vi idag har i Sverige av sproblemet «- göra något åt. 


\section{Implikationer för forskning}

Frågan om skol- och utbildningssituationen för svenska fosterbarn är den samma som i andra länder, kan inte besvaras med tillräcklig säkerhet. Här behövs till at börja med studier som undersöker problemets omfattning. Vidare är det nödvändigt att sortera i fosterbarnspopulationen, att finna olika grupper med olika problembelastning, bakgrund $\mathrm{m} m$ för att få en rudimentär bild av problemets komplexitet (se FletcherC ampell \& H all, 1990 för exempel på en sådan fruktbar uppdelning). Barn i samhällsvård är en heterogen population vilket bl.a. Roy Parker (1987) har hävdat med emfas. Vidare är orsaksfrågan enligt min mening fortfarande åtminstone delvis obesvarad. Det finns olika möjligheter att närma sig dessa frågeställningar. Jackson (1994) beskriver en studie där fosterbarn som är framgångsrika i skolan jämförs med en grupp som har betyd ande svårigheter, vilket kan vara en vägtill ökad förståelse.

\section{Implikationer för tillsyn}

Mot bakgrund av lagstiftningens utformning och intentioner är det - särskilt med tanke på den brittiska debatten - närmast märkligt att svenska tillsynsmyndigheter inte har visat något intresse för fosterbarns (och omhändertagnas barns) skola och utbildning. Detta del visi kontrast till SiS, Statens Institutionsstyrelse, som ansvarar för §12-hemsvården av ungdomar. SiS finansierar i skrivande stund en undersökning om skolans roll i vården av sin mål grupp. Vård som innehåller olika former av skol-/utbildningsinsatser verkar utifrån utländska forskningserfarenheter verkar vara en lovande utvecklingsväg för behandling av aso- ciala ungdomar (Daleflod, 1996), men också för mindre belastade tonåringar. J ohn Triseliotis $\mathrm{m} \mathrm{fl}$ (1995b) fann i en studie av 116 tonårsplaceringar i dygnsvård att såväl vårdens stabi litet som ungdomarnas egna utvärdering av behandlingen var betydligt bättre vid placeringar i institutionsvård med inbyggd skola (residential schools) än i annan institutionsvård.

\section{Implikationer för praktiken}

Den sociala forskningen har få färdiga, detaljerade recept på framgångsrika insatser till de kommuner som i egna uppoöljningar finner att det finns lokala problem och som vill göra något åt det. Här är (som så ofta) vi for skare mer lågmäld a än i våra beskrivningar av shur det är « I Sverige finns, vad jag vet, inga studier som berör ämnesområdet ut ett insatsperspektiv. Även britterna har få utvärderade svar på vad som kan göras för att förbättra den dystra bilden. Allmänt verkar man ha försökt arbeta för en attitydförändring hos socialarbetare och vårdansvariga myndigheter, i första hand mot ökad uppmärksamhet på problemet. A merikanerna har varit mer pragmatiska i att omsätta forskningserfarenheter i handling. Erfarenheterna från USA 's semancipationsprogram《 är mycket lovande, även om vi idag inte vet vad som är överförbart till svenska förhållanden, och vad som inte är det. Den amerikanske barnavårdsforskaren Richard Barth har i en artikel uttryckt förvåning över att den svenska socialtjänsten saknar speciella insatser som förbereder samhällsvårdade barn på livet efter 18-årsdagen (Barth, 1992).

Sannolikt finns det mycket vi kan direkt kopiera från de amerikanska erfarenheterna 
men det tar tid att först bestämma vad och sedan att genomföra något $i$ organiserad form. Jag tror att socialarbetare, skolpersonal och andra berörda också måste prova sig fram, använda egen praxiskunskap förutom det man lära från forskning och internationella exempel, samt att utvärdera det man försökt göra. Med tanke på att den kunskap som finns är begränsad, är det viktigt att insatser redan från början designas för utvärdering, t.ex. i lokala projekt.

Ett första stegär kanske att få chefers och politikers uppmärksamhet på att det troligen finns en situation som inte rimmar med lagstiftarnas uttalade ambitioner, och undersöka detta lokalt. Nästa steg är - om det finns anledning härtill - att få sanktioner för olika former av kompensatoriska sat sningar. Detta innebär de facto utgifter, även om dessa blir marginella jämfört med en kommuns totala kostnader för barn- och ungdomsvården.

M åste allt göras av socialtjänsten? Kanske är någon annan organisation intresserad av at skapa, administrera och jaga pengar till en stipendiefond för fosterbarns utbildning - likt vad som finnsi USA - t.ex. för in- köp av persondatorer eller för vuxenstudier? Är detta en uppgift som Allmänna Barnhuset skulle vara intresserad at ta på sig? Finns det lagliga eller andra hinder för varje svensk kommun att varje år ge ett frivilligt bidrag till en sådan fond, summan beroende på t.ex. hur många barn man har placerade i samhällsvård?

Kanske är frågorna om fosterbarns skola och utbildning ett område där socialarbetare, föräldrar, fosterföräldrar, skolfolk, politiker och forskare relativt lätt kan finna varandra i ett målinriktat arbete. Mycket i barn- och ungdomsvården verkar annars ofta svårt att påverka, framförallt de förhållanden och tragedier som framtvingar samhälleliga interventioner.

Slutligen: jag har nära nog inte alls berört pedagogisk teori och forskning i översikten p g a okunskap och bristande överblick. Vad kan vi lära därifrån? Det finns sannolikt många exempel där kunskap från pedagogisk forskning har applicerats på grupper som är jämförbara med fosterbarn, insđtser som har utvärderats vetenskapligt. En översi kt av såd ana erfarenheter vore både mycket välkommen och värdefull.

\section{Summary Scooling and education of foster cildren}

Educational problems of foster children have in recent years increasingly become an issue of keen interest in Britian and the US, for social research as well as for practice. Studies in several countries have uniformly shown that foster children as a group are poor achievers in school and run a strong risk of leaving the care system as loweducated young adults. In Sweden this issue has to a large extent been neglected by local as well as national child welfare authorities and al so by Swedish research. This is rather surprising since Swedish child welfare legislation has for decades explicitly 
pointed out education as a matter of priority in Swedish foster care.

The article is a review of international research - mainly British and American - on education of foster children and aims to place educational issues in foster care on the national agenda for practice as well as research. It contains an outline of the prevalence of problems and reviews the discussion in international literature on the aetiology of foster children's educational difficulties. Attempts to mitigate the problems and further educational attainments of foster children are described as well as results from evaluations of these. Finally, there is a call for a much more vital focus on educational issues in Swedish foster care policy, practice and research.

\section{Referenser}

AldgateJ (1990): Foster children at school: success or failure? A doption \& Fostering, vol 14, no 4, pp 38-49.

Aldgate J , C olton M, G hate D \& Heath A (1992): Educational attainment and stability in longterm foster care. C hildren \& Society 1992 6:2, pp 91-103.

Aldgate J , Heath A, Colton M \& Simm M (1993): Social work and the educ ation of children in foster care. A doption \& Fostering, vol 17, no 3, pp 25-34.

Alin-Å kerman B (1978): A doptivbarn-foster barn. En studieav en gr upp barn som vistats på spädbarnshem. M US-projektet, Högskol an för lärarutbildning i St ockholm, institutionen för pedagogik, rapport 5/1978.

Andersson G (1984): Små barn på barnhem. D oktorsavhandling. M almö: Liber.

Andersson G (1995): Barn i samhällsvård. Lund: Studentlitteratur.

A ronsson M \& Hagberg B (1993): H ur har det gått för de al kohol skad ade barnen? L äkartidningen, vol 90, nr 23, pp 2214-2219.

Ayasse R (1995): A dressing the needs of foster children: the foster youth services program. Social Work in Education, vol 17, no 4, pp 207216.

Barbalet M (1983): Far from a low gutter girl. Melbourne: 0 xford University Press.

Barth J (1986): Emancipation services for ad olescents in foster care. Social W ork , 31, M ayJune 1986, pp 165-171.
BarthJ (1990): O n their own: the experiences of youth after foster care. $C$ hild and $A$ dol escent Social Work, vol 7, no 5, pp 419-440.

BarthJ (1992): C hild welfare services in the United States and Sweden: different assumptions, laws and outcomes. Scandinavi an Journal of Welfare, 1992:1, pp 36-42.

Barth R \& Berry M (1988): A doption \& disr uption. $R$ ates, risks and responses. N ew York: A Idine de G ruyter.

Berglind R (1956): H ur går det för fosterbarnen? Sociala M eddelanden 1956, nr 8, pp 493-519.

Berridge D (1994): Foster and residential care reassessed: a research perspective. $C$ hildren $\&$ Society 8:2, pp 132-150.

Berridge D (1997): Foster care. A research review. London: The Stationary 0 ffice.

Berridge D \& C leaver H (1987): Foster home breakdown. 0 xford: Basil Blackwell.

Berry M \& Barth R (1990): A study of disrupted adoptive placements of ad olescents. $C$ hild Welfare, vol LXIX, no 3, pp 209-225.

Biehal N , C layden J, Stein M \& WadeJ (1992):

Prepared for living? London: National Children's Bureau.

Biehal N , C layden J, Stein M \& Wade J (1995):

M oving on. Young people and leaving careschemes. London: H M SO .

Blyth E \& M ilner J (1993): Exclusion from school: a first step in exclusion from society? $C$ hildren and Society vol 7, no 3, pp 255-268.

Bohman I (1972): B arn i framtidshem. Psykologex- 
amensarbete. Stockholms U niversitet: ped agogiska institutionen, Forskningsrapport nr 6 .

Bohman M (1970): A dopted children and their families. Stockholm: Proprius.

Bohman M (1971): A comparativestudy of adopted children, foster children and children in their biological environment born after undesired pregnancies. Acta Pediatrica Sc andinavia, suppl 221.

Bohman M (1973): A doptivbarn och derasfamiljer. Stockholm: Almqvist \& Wiksell. M onografier utgivna av Stockholms kommunal förvaltning nr 34.

Bohman M \& Sigvardsson S (1980a): A prosepective, longitudinal study of children registered for adoption. A 15-year follow-up. Acta Psychiatrica Scandin avia, 61, pp 339-355.

Bohman M \& Sigvardsson S (1980b): Negative social heritage. A doption \& Fostering, no 3/1980, pp 25-31.

Bohman M \& Sigvardsson S (1980c): Umeåundersökning: barn i fosterhem klarade sig sämst. Socionomen $n r$ 19/1980, pp 8-9.

Brickman A , Dey S \& C uthbert P (1991): A supervised independent-living orientation program for adolescents. Child Welfare, vol LXX, no 1, pp 69-80.

Brodie I \& Berridge D (1996): School Exclusion.. Research themes and issues. Luton: University of Luton Press.

Börjeson B \& Håkansson H (1990): H otade-försummade - övergivna. Stockholm: Raben \& Sjögren.

Carlsson I (1972): Barn i fosterhem följda under 20 år. Licentiatavhandling. G öteborgs Universitet, Pedagogiska institutionen.

C autley P W (1980): N ew foster parents. The first experience. N ew York: Human Sciences Books.

C ederström A (1990): Fosterbarns an passning en relationsproblematik. Doktorsavhandling. Stockholms Universitet: Pedagogiska institutionen.

C ederström A (1994): Foster barns an passning II . Delstudie 1. Stockholms U niversitet: Pedagogiska institutionen.

Christoffersen M (1993): A nbragte börns livsför - löp. Köpenhamn: Socialforskningsinstituttet, rapport 93:11.

Clarke A M \& Clarke A D B (1976): Early expe rience- myth and evidence. London: 0 pen Books.

Cliffe D \& Berridge D (1991): C losing children's homes: an end to residenti al childcare? London: National children's Bureau.

Colton M , Aldgate J \& Heath A (1991): Behavioral problems of children in and out of care. Social Work and Social Sciences R eview, 2, pp 177-191

Colton M \& Heath A (1994): Attainment and behaviour of children in care and at home. $0 x$ ford Review of Education, vol 20, no 3, pp 317327.

Colton M, Heath A, A ldgateJ (1995): Factors which influence the educational attainment of children in foster family care. Community A Itern atives. Intern ation al J ournal off amily Care, vol 7, no 1, pp 15-36.

Cook R (1997): A re we helping foster care youth prepare for their future? I Duell Berrick J, Barth R \& G ilbert N (eds): C hild welfareresearch review, vol 2. New York. Columbia University Press.

Daleflod B (1996): Är det möjligt att rehabilitera kriminella ungdomar? I A rmelius B- $\AA$, Bengzon S, Ryd el ius P-A, Sarnecki J \& Söderholm-Carpelan $\mathrm{K}$ (red): Vård av ungdomar med sociala problem - en forskningsöversikt. Stockholm: Liber Utbildning/SiS.

Dalianis-Karambatzakis M (1994): C hildren in turmoil during the G reek civil war 1946-49. Doktorsavhandling. Stockholm: Karolinska Institutet.

Dept of Health Social Services Inspectorate and O ffice for Stand ards in Education (1995): The education of children who arelooked after by local authorities. London: Dept of Health Social Services Inspectorate and 0 ffice for Standards in Education

Djurfeldt $M$, Ivehammar $E \&$ T igerström A (1976): En gr upp fosterbarns upplevelser av sin situation. Psykologexamensarbete. G öteborgs Universitet, pedagogiska inst, psykologexa- 
mensarbete. $\mathrm{nr}$ 88/1976.

Dolan D \& O 'N eill L (1983): H el ping the foster child at college and at preparatory school. N ew York Times, 13 nov 1983, p 15.

Dumaret A (1985): IQ , scholastic performance and behaviour in sibsraised in contrasting environments. Journal of C hild Psychology \& Psychiatry, no 4/1985, pp 553-580.

Ekström M (1993): Sociol ogiska förklaringar och variabelanalysens gränser. Sociologisk Forskning nr 2, pp 26-58.

Elder G (1974): C hildren of the great depression. C hicago. C hicago University Press.

Elder G (1986). Military times and turning points in men's lives. Developmental Psychology, 22, pp 233-245.

Eriksson M , Billing L, Steneroth $G \&$ Zetterström $R$ (1989): Health and devel opment of 8-year old children whose mothers abused amphetamine during pregnancy. Acta Paedriatica Scandinavia.78/1989, pp 944-949.

Essen J, Lambert L \& Head J (1976): School attainment of children who have been in care. C hild: care, health and devel opment, 1976, 2, pp 339-351.

Fanshel D , Finch S\& G rundy J (1990): Foster children in a lifecourse per spective. N ew York: Columbia University Press.

Fanshel D \& Shinn E (1978): C hildren in foster care. New York: C olumbia University Press.

Ferguson T (1966): C hildren in care- and after . London: 0 xford University Press.

Festinger T (1983): N ooneasked us.... A postscript to foster care. N ew York: Columbia University Press.

Fletcher-C ampbell F \& Hall C (1990): C hanging schools? C hanging people? The education of children in care. Slough: National Foundation for Educational Research.

Fox M \& A rcuri K (1980): C ognitive and academic functioning in foster children. $C$ hild Welfare, vol LIX, no 8, pp 491-496.

G arnett L (1992): L eaving care and after. London: National children's Bureau.

G oerge R, Van Voorhis J, G rant S, C asey K \& Robinson M (1992): Special-education expe- riences of foster children: an empirical study. C hild Welfare, vol LXXI, no 5, pp 419-437.

Grimshaw R \& Berridge D (1994): Educating disruptivechildren. London: $\mathrm{N}$ ational C hildren's Bureau

Heath A, C olton M \& A ldgateJ (1989): The educational progress of children in and out of care. British Journal of Social Work, vol 19, no 6, pp 447-460.

Heath A , Colton M \& A ldgateJ (1994): Failure to escape: a longitudinal study of foster children's educational attainment. British J ournal of Social Work, 24/1994, pp 241-260.

Hedberg A-M (1964): Principerna för bedömning och urval av adoptivbarn och adoptivföräldrar. Socialmedicinsk Tidskrift 41, nr 4, pp 161-169 HessleS (1988): Familjer i sönderfall. G öteborg. Norstedts.

Holt M I (1994): T heorphan trains. Placing out in A merica. Lincoln, N ebraska: Bison Books/University of N ebraska Press.

Howe D (1995): Adoption and attachment. A doption \& Fostering, vol 19, no 4, pp 7-43.

Jackson S(1987): The education of children in care. University of Bristol: Bristol Papers in Applied Social Studiesno 1.

Jackson S (1988): Education and children in care. A doption \& Fostering, vol 12, no 4, pp 6-10.

Jackson S (1994): Edu cating children in residential and foster care. 0 xford Review of Education, vol 20, no 3, pp 267-279.

Jones M A \& M oses B (1984): West Virginia's former foster children. Their experienceand their lives as young adults. New York: C hild Welfare League. rapport till Dept of Human Services, State of West Virginia.

Lagerberg D (1984): Fosterbarn, forskning, teori och debatt. Stockholm: Skeab Förlag. Lagerberg D, M ell bin T, Sundelin C \& Vuille J-C (1994): G rowing up in Uppsal a. The »N ew morbidity «in the adolescent period. A longitudinal epidemiological study based on school data and some external sources. A cta Paediatrica, vol 83, June, 1994, suppl 398.

Lewis M , Feiring C , M cG uffog C \& Jaskir J (1984): Predicting psychopathol ogy in six-year 
oldsfrom early social relations. C hild D evel opment, 1984, 55, pp 123-136.

$M$ aas $H$ (1969): C hildren in long term foster care. Child Welfare, vol X LV III, no 6, pp 321-333.

$M$ aas $H$ \& Engler $R$ (1959): C hildren in need of parents. New York: Columbia University Press.

Mech E (1994): Foster youths in transition: research perspectives on preparation for independent living. C hild Welfare, vol LXX III, no 5, pp 603-623.

Menmiur R (1994): Involving residential social workers and foster carersin reading with young people in their care: the PRA ISE reading project. Oxford Review of Education, vol 20, no 3, pp 329-338.

Newsome M (1992) The impact of the past on the care and education of deprived children. C hildren \& Society, 6:2, pp 151-162.

Packman J (1986): W ho needs care? Social-works decisions about children. 0 xford: Basil Blackwell.

Palmer S (1979): Predicting outcome in long-term foster care. Journal of Social Ser vice Research, vol 3(2), pp 201-214.

Parker R (1987): A forward look at research on the child in care. Bristol: University of Bristol, School of Applied Social Studies.

Parker R, W ard H , Jackson S, A ldgate J \& Wedge P (eds) (1991): Looking after children: assessing outcomes in child care. London: H M SO .

Patterns \& $O$ utcomes in C hild Placement (1991): London: HM SO .

Pilling D (1990): Escape from disadvantage. London: The Fal mer Press.

Proch K \& Taber M (1987): A lienated adolescents in foster care. Social Work R esearch \& A bstracts, 23/2, pp 9-13.

Q uinton D \& Rutter M (1976): Early hospital admissions and later disturbances of behaviour: an attempted replication of D ouglas'findings. Developmental M edicineand C hild N eurology, vol 18, pp 447-459.

Q uinton D \& Rutter M (1988): Parenting breakdown. Aldershot: Newbury.

Rosenfeldt A, Pilowsky D, Fine P, Thorpe M, Fein $E$, Simms M, Halfon N, Irwin M , A lfaro J, Saletsky
R \& N ickman S(1997): Foster care: an upd ate. Journal of American Acad. C hild \& A dolescent Psychiatry, 36:4, pp 448-457.

Rosenthal J, Schmidt D \& C onner J (1988): Predictors of special need sadoption: an exploratory study. C hildren and Youth Services Review, vol 10, pp 101-117.

Rowe J, C ain H, Hundleby M \& Keane A (1984): Long term foster care. London: Batsford/BA A F. RoweP (1983): Bridging the gap: from foster care to independent living. $C$ hildren Today, SeptOct 1983, pp 28-29.

Runyan D \& G ould C (1985): Foster care for maltreatment. II. Impact on school performance. Pediatrics, vol 76, no 5, pp 841-847.

Rushton A \& Treseder J (1986): Developmental recovery. A doption \& Fostering, vol 10, no 3, pp 54-57.

Rutter M (1990): Psychosocial resilience and protective mechanisms. I rolf J , M asten A, C icchetti D, Nuecterlein K \& Weintraub S (eds): Risk and protectivefactor sin the development of psychopathology. C ambridge: C ambridge University Press.

Rutter M \& Q uint on D (1984): Long term followup of women institutionalized in childhood: factors promoting good functioning in adult life. British Journal of Devel opmental Psychology, 2, pp 191-204.

Rydelius P-A (1996): Skolans betydel se för asocialitetsutveckling. I A rmelius B- $\AA$, Bengzon S, Rydelius P-A , Sarnecki J \& Söderholm-C arpelan K (red): Vård av ungdomar med sociala problem en forskningsöversikt. Stockholm: Liber Utbildning/SiS.

Salonen T (1993): M argins of welfare Doktorsavhandling. Hällestad: H ällestad Press.

Sameroff A, Seifer R, Barocas R, Zax M \& G reenspan S (1987): Intel ligence quotient scores of 4year old children: social-environmental risk factors. Pediatrics, 1987/79, pp 343-350.

Sawyer R \& Dubowitz (1994): School performance of children in kinship care. C hild A bu se $\&$ Neglect, vol 18, no 7, pp 587-597.

Scannapieco M , Schagrin J \& D cannapieco T (1995): Independent living programs: do they make a difference? $\mathrm{C}$ hild and A dol escent Social 
Work Journal, vol 12, no 5, pp 381-389.

Scarr S\& G rajek S(1982): Similarities and differences among siblings. I Lamb $M \&$ SuttonSmith B (eds): Sibling realtion ships: their nature and significanceacross the lifespan Hillsdale, $\mathrm{NJ}$ : Lawrence Erl baum A ss Publ .

SC B (1993): H ögskol eutbildade i Sver ige. Ö rebro:

SC B, Siffror om högskol an, no 14.

Schaffer R (1990): M aking decisionsabout children. 0 xford: Basil Blackwell.

Schiff M, Duyme M , Dumaret A, Stewart J, Tomkiewics S \& Feingold J (1978): Intel lectual status of working class children adopted into uppermiddle classfamilies. Science, vol 200, June 1978, pp 1503-1504.

Schiff M , Duyme M, Dumaret A \& Tomkiewics S (1982): How much could we boost scholastic achivements and IQ -scores? A direct answer from a French ad option study. International Journal of C ognitivePsychology, no 12/1982, pp 165-196.

Stein M \& C arey K (1987): L eaving care. O xford: Basil Blackwell.

Svenska Kommunförbundet/C irkulär 1997:202: Placeringskommunens ansvar för särskilda stödinsatser i barnomsorg och skola, SoL $\S 72$ a.

TimberlakeE, Pasztor E, Sheagren, Clarren \& Lammert M (1987): Adolescent emancipation from foster care. $C$ hild and $A$ dol escent Social Work, vol 4, no's 3\&4, pp 116-129.

Timberlake E \& Verdieck M J (1987): Psychosocial functioning of ad olescents in foster care. The Journal of C ontem porary Social Work, vol 68, April 1987, pp 214-222.

Tizard J \& Hewison J (1980): Parental involvement and reading attainment. British J ournal of Educational Psychology, 52, pp 209-215.

Tizard J, Schofield W \& Hewison J (1982). C ollaboration between teachers and parents in assisting children's reading. British J ournal of Educational Psychol ogy, 54, pp 1-15.

Triseliotis] (1980): G rowing up in foster care and after. I Trisliotis) (ed): N ew developments in foster careand adoption. London: Routledge \& Kegan Paul.

Triseliotis] (1983): Identity and security in adop- tion and long-term fostering. A doption \& Fostering, vol 7, no 1, pp 22-31.

TriseliotisJ \& Russel J (1984): H ard to place. London: Heinemann Educational Books.

Trisel iotis] , Borland M , Hill M \& Lambert L (1995a): Teenagersand theSocial Work Services. London: H M SO .

Trisel iotis], Sellick C \& Short R (1995b): Foster care. T heory and practice. London: Batsford/ BAAF.

Vinnerljung B (1992): 235 syskon med olika uppväxtöden - en retrospektiv aktstudie. Lunds Universitet: Meddleanden från Social högskolan 1992:5.

Vinnerljung B (1996a): Fosterbarn som vuxna. D oktorsavhandling. Lund: A rkiv Förlag.

Vinnerljung B (1996b): Svensk forskning om foster barnsvård - en översikt. Stockholm: Liber Utbildning/CUS.

Vinterhed K (1985): D eandra föräldrarna. Stockholm. Skeab.

Vinterhed $K$, Börjeson B, C ederström A, Fredin E, Hessle M \& HessleS (1981): Barn i kris. En bok om barn och separation. Stockholm: AW E/G ebers.

Wald M , C arlsmith J \& Leidermann P (1988): Protecting abused and neglected children. Stanford, Ca: Stanford University Press.

Walker T G (1994): Educating children in the public care: a strategic approach. 0 xford Review of Education, vol 20, no 3, pp 339-347.

Ward H (1995): Revising the content of the assessment and action records. I Ward H (ed): L ooking after children: Research into practice. London: HMSO.

Ward H (1995) (ed): Looking after children: Re search into practice. London: H M SO .

Williams T \& Kornblum W (1986): Growing up poor. Lexington, $M$ a: Lexington Books.

Zeuner L (1990): Normer i skred. U ngdom skriminalitetens socialeog kulturelleaspekter. Köpenhamn: Social forskningsinstituttet, publikation nr 90:12.

Zimmerman R (1982): Foster carein retrospect. N ew O rleans, Tulane Studies in Social Welfare. 